\title{
Flat-based over-the-scope clip-assisted endoscopic full-thickness resection of a duodenal neuroendocrine tumour: a safe alternative to endoscopic submucosal dissection
}

Endoscopic submucosal dissection (ESD) results in higher numbers of complications when used in the duodenum compared with other locations owing to a variety of factors [1]. Here, we demonstrate endoscopic full-thickness resection (EFTR) using the Padlock clip defect closure system as an alternative technique for en bloc resection of a duodenal neuroendocrine tumor (NET) of $<1.5 \mathrm{~cm}$. Most of the previous literature has reported the use of the Ovesco over-thescope clip system or the new full-thickness resection device for resection of NETs within the duodenum [2-4]. To the best of our knowledge, this is the first case to be reported in which the padlock system was used for EFTR of a NET $>10 \mathrm{~mm}$ in size.

A 56-year-old man presented with mild upper abdominal pain for 6 months. An upper gastrointestinal endoscopy showed a $1.5-\mathrm{cm}$ subepithelial lesion in the duodenal bulb ( $\mathbf{F i g} \mathbf{1}$ ). Narrowband imaging (NBI) showed a normal mucosal pattern. Endoscopic ultrasound (EUS) examination showed a homogeneous hypoechoic mass of $1.2 \times 0.6 \mathrm{~cm}$ arising from layer 3 , suggestive of a NET ( Fig.2). We decided to perform EFTR of the mass. The lesion edges were marked with argon plasma coagulation (APC). Subsequently, the Padlock over-thescope clip system (16-mm diameter) was accurately deployed at the base of the lesion, after it had been totally suctioned into the cap ( $>$ Fig. 3 ; $\triangleright$ Video 1 ). A 20 $\mathrm{mm}$ polypectomy snare was then used to grasp and resect the lesion at its base, just above the Padlock clip. The cut surface was observed, with the Padlock clip in situ, and the cut edges were free of any macroscopically visible tumor tissue, with no evidence of bleeding. The patient was kept in hospital for overnight observation and was discharged the next day on a normal diet. Histopathology subse-

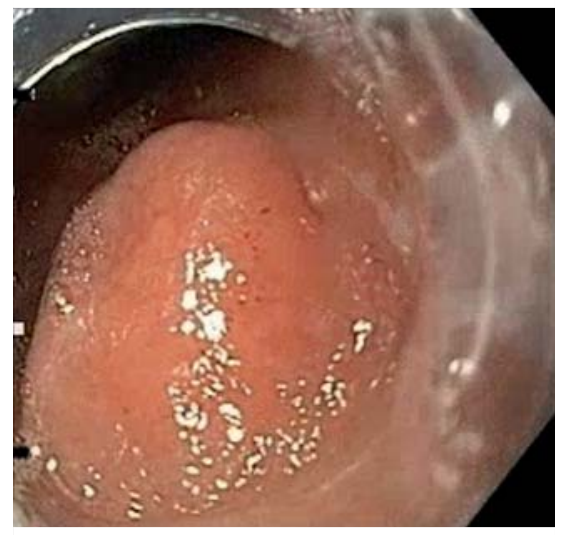

- Fig. 1 Upper gastrointestinal endoscopy image showing a $1.5-\mathrm{cm}$ subepithelial lesion in the posterior wall of the duodenal bulb.

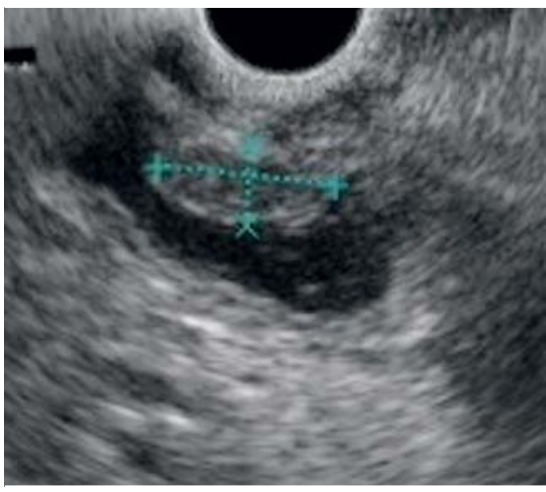

- Fig. 2 Linear endoscopic ultrasound image shows a homogeneous hypoechoic mass arising from layer 3 , with features suggestive of a neuroendocrine tumor.

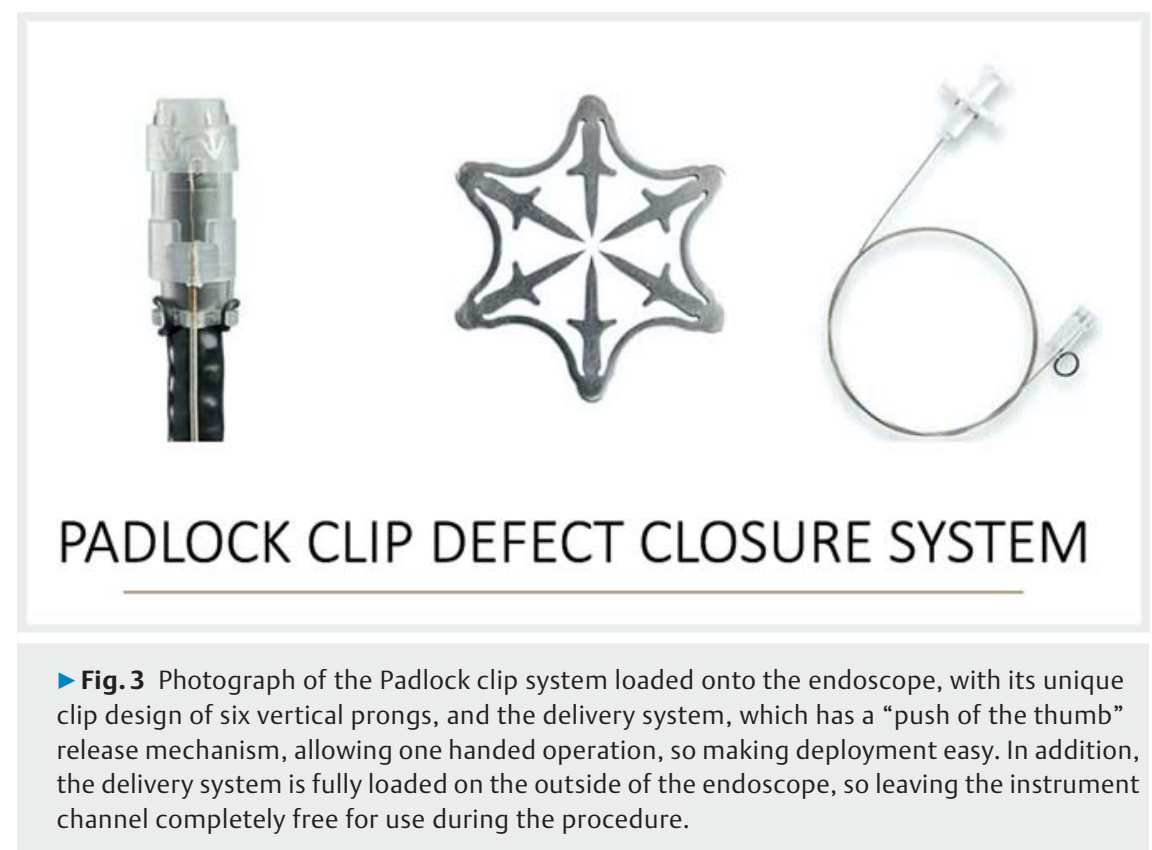

quently showed a well differentiated NET with uninvolved margins ( $>$ Fig. 4 ).

EFTR can be a safe, less cumbersome, and less time-consuming alternative to ESD for subepithelial lesions in the duodenum. It can be safely performed in centers with less experience in duodenal ESD.
Endoscopy_UCTN_Code_CCL_1AB_2AZ_3AB

Competing interests

The authors declare that they have no conflict of interest. 


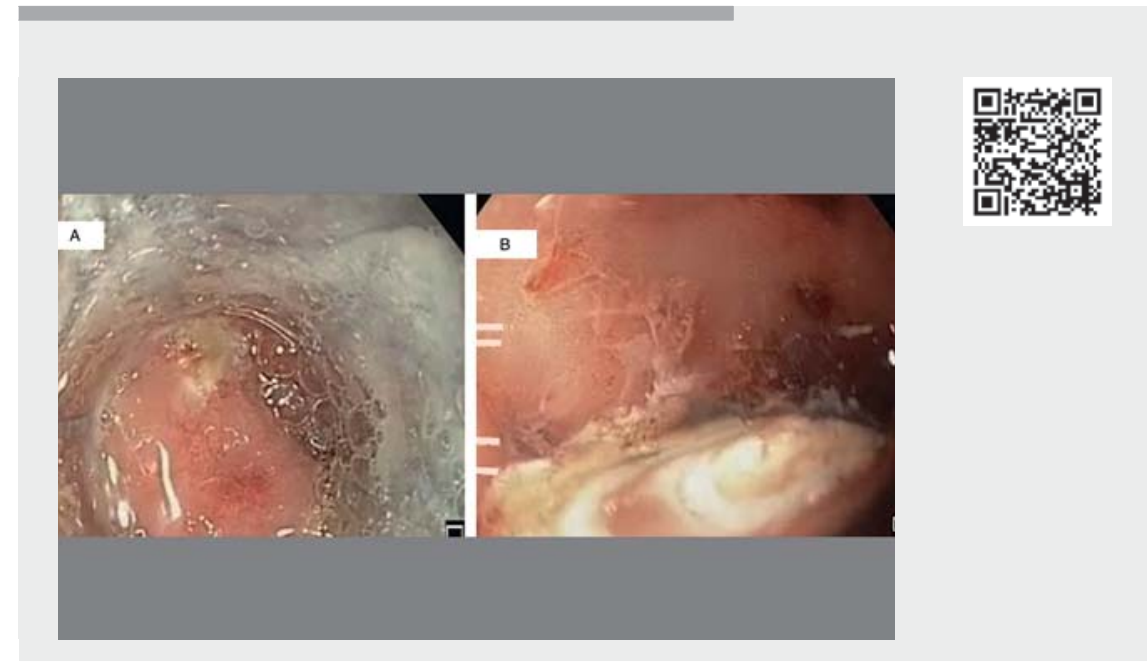

$\square$ Video 1 Video demonstrating accurate delineation of a duodenal neuroendocrine tumor and use of the Padlock clip defect closure system for endoscopic full-thickness resection of the lesion.
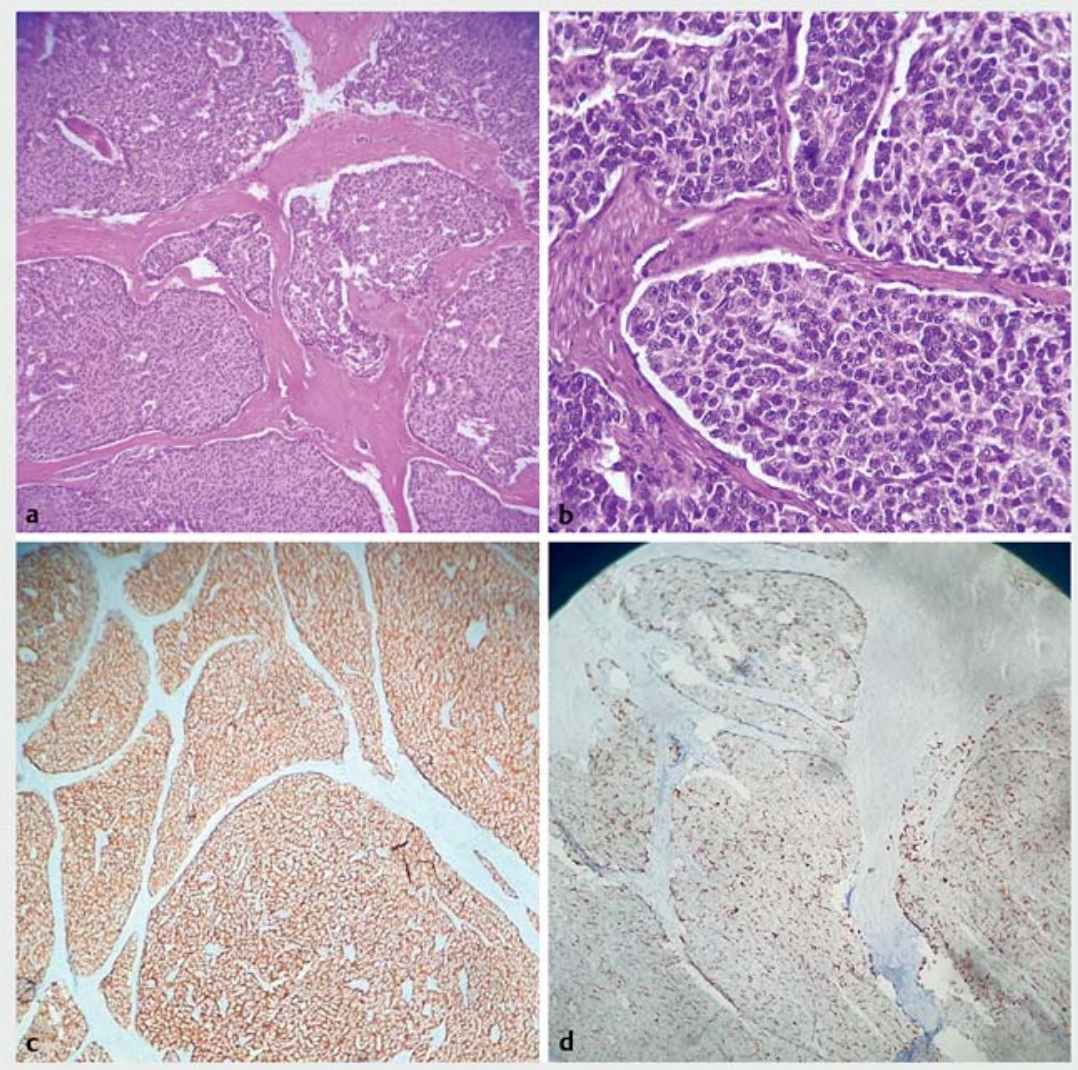

- Fig. 4 Histopathology images showing: a, b a well differentiated neuroendocrine tumor with uninvolved margin, suggestive of an $\mathrm{R} 0$ resection; $\mathrm{c}$ immunohistochemical staining with positivity for chromogranin and synaptophysin; d a Ki67 index of $1 \%$, suggestive of favorable histology.
The authors

Nikhil Sonthalia, Bhavik Bharat Shah, Mahesh Kumar Goenka

Institute of Gastrosciences and Liver diseases, Apollo Gleneagles Hospital, Kolkata, India

Corresponding author

\section{Mahesh Kumar Goenka, MD}

Institute of Gastrosciences \& Liver diseases, Apollo Gleneagles Hospital, 58, Canal

Circular Road, Kolkata, West Bengal 700054, India

mkgkolkata@gmail.com

\section{References}

[1] Marques ], Baldaque-Silva F, Pereira P et al. Endoscopic mucosal resection and endoscopic submucosal dissection in the treatment of sporadic non-ampullary duodenal adenomatous polyps. World J Gastrointest Endosc 2015; 7: 720-727

[2] Andrisani G, Di Matteo FM. Endoscopic fullthickness resection of duodenal lesions (with video). Surg Endosc 2020; 34: 18761881

[3] Bauder M, Schmidt A, Caca K. Endoscopic full-thickness resection of duodenal lesions - a retrospective analysis of 20 FTRD cases. United European Gastroenterol J 2018; 6: 1015-1021

[4] Tashima T, Ryozawa S, Tanisaka Y et al. Endoscopic resection using an over-the-scope clip for duodenal neuroendocrine tumors. Endosc Int Open 2021; 9: E659-E666

\section{Bibliography}

Endoscopy 2022; 54: E391-E393

DOI 10.1055/a-1546-9958

ISSN 0013-726X

published online 9.8.2021

(c) 2021. Thieme. All rights reserved.

Georg Thieme Verlag KG, Rüdigerstraße 14,

70469 Stuttgart, Germany 


\section{CORRECTION}

Flat-based over-the-scope clipassisted endoscopic full-thickness resection of a duodenal neuroendocrine tumour: a safe alternative to endoscopic submucosal dissection Sonthalia N, Shah BB, Goenka MK et al. Flat-based over-the-scope clip-assisted endoscopic full-thickness resection of a duodenal neuroendocrine tumour: a safe alternative to endoscopic submucosal dissection.

Endoscopy 2021, doi:10.1055/a-15469958

In the above-mentioned article, the title has been corrected. Correct is: Flat-based over-the-scope clip-assisted endoscopic full-thickness resection of a duodenal neuroendocrine tumour: a safe alternative to endoscopic submucosal dissection. This was corrected in the online version on April 14, 2022. 